Kohl: a Journal for Body and Gender Research

Vol. 2, No. 1 (Summer 2016)

\title{
External Pleasure, Internal Violence? A Conversation on Conformity, Sex Work, and Language
}

\author{
Jana Nakhal
}

"Openings" is a corner in Kohl that aims at presenting a collective experience in thinking and writing, through publishing excerpts of recorded discussion sessions among those who work in a particular field or topic, or people who are interested in it. The discussions take place in the presence of a mediator who directs the debate then extracts the main ideas to write them and publish them in a summarized article.

"Openings" aims at showing and exposing different and even opposing points of view and opinions, and opening the floor for the expression of a large number of people who have valuable experiences and opinions, and who do not have the time or the will to write.

"Openings" intends to challenge the traditional methods of knowledge production, especially within academic circles that are often characterized by exclusivity, individuality, selectivity, and complex requirements.

It also hopes to expose and activate the intellectual wealth that characterizes the discussions and collective thinking, and then to incorporate the public audience in the suggested issues. This experience combines journalism and public discussions by tackling subjects that are usually categorized as academic or "elitist." This way, "Openings" allows for the revaluation of writing, publishing, and representation politics, and encourages those who participate to exchange their experiences and their ideas and to develop them openly and publically. This article constitutes the first attempt at "Openings," and will be followed by other articles that allow its development and the refining of its technical aspect, its chosen topics, the characteristics of those who participate in it, and the methods of writing, publishing, and drafting. 
Pleasure cannot have a generic recipe. While the complexities of intimacy and enjoyment unfold, we find ourselves questioning the conventional, the accepted, and the conditioning-induced trend.

It is sometimes by asking why things happen the way they do, or by existing, that we resist the violent encryption of the body and ideas: we exist as a refusal to hegemony itself.

Linking resistance with pleasure, whether politically or sexually, we tend to dissociate it from a mainstream understanding of violence.

In this discussion, we tried to reclaim sites of pleasure and sexuality in environments usually perceived as subjugating, and we tried linking them to behaviors and expectations, as well as our uses of the language, our perceptions of the land, and sexual liberation.

The discussion session was held at the office of the Arab Foundation for Freedoms and Equality on the $26^{\text {th }}$ of May 2016 and lasted for three hours. This article includes short excerpts of the main ideas that were raised throughout the discussion.

When it comes to representation policies, it should be mentioned that the participators are speaking out of their personal experiences and opinions, and they, therefore, do not represent any side or group or association, and are only expressing their own views, even when they speak in plural.

Pseudonyms were used in this discussion to protect the privacy and safety of the participators.

If you would like to suggest an idea for discussion, or even host a discussion with a particular group of people in the "Openings" corner, you may contact the Kohl team at: info@kohljournal.org. 
Kohl 2.1

L.:

Tackling the intersections between violence and pleasure is very broad. We would have to define each and every single term, I think.

Jana: $\quad$ Each person can have her/his own definition of the terms.

L.:

Yes, exactly. When people usually put pleasure and violence together, which is my own perspective, they are not entirely mutually exclusive. But I think it is better if we narrow it down into a context.

Jana: I think it could be used in general relationships between "men" and "women," but we could also go into details of sexual relationships. From what I can see being a woman in Lebanon, in addition to readings I did, the idea of "dominion" is very interesting. We can start from there, talking about the existence of violence alongside pleasure in normalized relationships between "men" and "women" in general.

L.: $\quad$ Looking at it from the perspective of heterosexual/sexual, it is interesting to look at the concept of dominion. When we can perceive a particular type of violence to be pleasurable one way or another, within that dynamic, I don't think that we can be blatant. The disproportionate dynamics might appear clear but they generally are not.

Khalil: $\quad$ Even the way L. said it, it still is too broad. I think a good starting point to see the dynamics between pleasure and violence is to always link back to the social identity of the person, which is at the end of the day their political identity. Maybe we could link it to a specific feature, or something that can be measured or profiled, or else understanding what it really means would remain theoretical.

Jana: $\quad$ We can go on talking about what attributes define what women "are," and what men "are:" she is generally the "weak" and "fragile," and he is the "strong" one.

Khalil: $\quad$ So we are going to stick to the traditional gender roles?

Jana: $\quad$ This is where we are going to start. So according to this, we can say that he is the one who dominates and she is the one who enjoys being dominated.

Khalil: "He/she," I don't really know how much the relationship is clear-cut, whether between someone who is dominating and dominated, and someone who accepts the roles. I see that the dominated is complacent somehow and is compliant to that realm of dominion.

Jana: Or actually unaware. 
Khalil: $\quad$ Well, maybe aware and supporting it. So if I take the example of how I grew up, men in my family were not significant. You know they didn't have a role according to "what a man should be in a household," like the breadwinners and the decision-makers. Usually, they were the chaotic creatures. But actually the ones who kept this unit going on were the women: my mother, my grandmother, and my elder sister. And in my head, it wasn't ascribed to a specific gender role, although you learn it, because the family is surrounded by other families where you see the typical character of an adult male, and he is the one who works and takes care of the family, who is there to defend you, while if I want to take it personally, my father was the complete opposite example. I mean he was always drunk, never there, so absent, always the trouble-maker. And you see the women in my family running after the men...

Serena: $\quad$ And nurturing them

Khalil: $\quad$ Exactly, and correcting whatever they are doing. At the same time, the women in my family made it a point not to break the traditional form of respect, so whatever happens, "hayda bayyak, ${ }^{1}$ don't shout in his face."

Jana: $\quad$ And sometimes, "don't make them feel weak."

Khalil: $\quad$ Exactly, don't shake their conception of the self. And see, women there are supporting in a way this patriarchal ideology. I could feel it because I was so close to them and I used to hear the ranting and the silent resilience if you want that rarely float to the surface as an act of resistance. I think this is where violence and pleasure come together. It is not always about physical pleasure... Here it becomes social pleasure and I would say political pleasure. It is about whether you are satisfied with yourself and it pleasures you to play the role that is decided for you.

Jana: $\quad$ Exactly, this satisfaction comes from a certain social norm that is telling you "you should be like that because it means that you are a good mother, or a good wife," not because there is an actual satisfaction of you knowing and defining what your role is and what you should be doing in life.

L.: $\quad$ My first question to you Khalil: since you define pleasure as social pleasure in this conversation, then what is violence in that case? The second thing is about women acting the role. Just because women enforce these unspoken rules about gender, doesn't mean that they are the source. Women who have suffered this type of treatment know how difficult it would be if they didn't teach their daughters how to just stay in line. "Do it for your own good." They become their own guard. You don't need the man around you because you know that any moment there could be another man working on his behalf.

1 This is your father 
Kohl 2.1

Khalil: Sacrifice, it is not violence. It is a socially-accepted violence.

L.: $\quad$ It is horrifying

Khalil: $\quad$ Yes, of course. Honor crimes are an example of this. In a sense, they are glorified as the violence that occurs to you in case you started a shameful act; this violence is a remedy. When you describe the act, when you imbue it with other meanings and symbolic functions, it becomes easy for the word itself to be violent. In a way, this symbolic migration of the meaning or displacement of the meaning does the same with how you socially accept a social act as related to what really is or is not.

L.: $\quad$ True and I agree, but you seem to have a unidirectional approach to violence and pleasure: you can forget that violence can become pleasurable. But there is something that is slightly more complicated, where both of these things can occur at the same time. As a transgender man, I conformed to the expected [female] gender role for a while. On the surface, there was social pleasure; beneath the surface, there was internal violence. And both of these things were happening at once. If I had basic conditioning abilities, then I would consider the things I did that elicited a positive reaction from my mother and family as good. But are they? Because at the end of the day, when I go back home, I cannot stand to be with myself because this is a type of violence. If everyone around me is celebrating, it doesn't mean that there isn't an internal violence that no one can see.

Khali: I agree with you. I was not thinking about it as unilateral, but about the fact that it is a ritual and the fact that these instances are repeated. I don't think anything can exist outside the dynamics of conflict. It is always there. But you also cannot be at war all the time. When you need your peace, you have to find that place where you resort to this skinny thin source of pleasure to numb yourself and re-gather your energy and go back to battling with what is causing all this pain and violence.

Jana: In which ways do you think that there are some sort of resistance, fields, or spaces of resistance that are possible for individuals? And concerning the creation of these spaces of resistance, do they actually create support and a breakage in the cycle of dominion, or do they on the contrary create comfort zones where we can go on with our lives and leave everything else outside?

L.: $\quad$ The act of resistance itself is by not conforming to the violence around you. That is one act of resistance. Another one is in the "why," like when children come and ask you why and you cannot answer because they never stop asking "why." "Why we do the things that we do?" And the minute you ask "why," that is already a sign of resistance, and that is what leads you to spaces of resistance because that is when you want to start a conversation with 
the other person who asks why. That is the first act of resistance. It all seems so arbitrary, but then you start asking, it shakes them. And if you keep asking, you are going to drift away from that, and it can lead you if you actually want to answer those questions or find other questions that can help you answer that question. That's where you have those spaces.

Serena: $\quad$ The sign of resistance would actually be to exist. There are terrible social constructions; it is about patriarchy, capitalism, heterosexuality, so I think existing is to resist.

L.: $\quad$ It depends on who is doing the existing, right? Because for instance a heterosexual cisgender person exists, some people do exist, but through their existence, they are not resisting much. Consider the most privileged, white man, cis-gender, heterosexual, ablebodied, European. There are spaces like this when how it should be is kind of unspoken, but they do exist. You can pretty much compare it to an unpleasant reminder that "shit, these people exist." And these people are still doing things, which they might not do successfully but they are still there.

\section{SEXUALIZING}

Jana: If we are to talk about bodies of women inside churches, mosques, and temples, for some, it is a duality: women's bodies are sexualized on beaches, women's bodies are not sexualized within religious spaces. And I say that this is exactly what is not true. The covering or uncovering of "something" doesn't deny its presence; it sometimes enforces the presence of what "needs" to be hidden, in this case, the body's sexuality.

L.: $\quad$ That wholly depends on who is doing the observation. For instance, children can be sexualized, like covering the nipples of baby girls and tiny toddlers at the beach. And I think if you are doing this to circumvent some pervert looking at your child, and you think that this is the norm, there is a problem here. So it relates to women who are veiled and women who are not. Women's bodies are sexualized in any form.

Jana: $\quad$ This is what I meant: them being covered in some places is not different from them being totally uncovered in other places.

L.: $\quad$ Let me give you an example. Recently, there are trans-bathroom bills exploding all over the U.S., for or against gender-neutral bathrooms. One politician was discussing how ridiculous it is that we should let trans-gender people go to the bathroom that they identify with. The issue was: "Think of all the men who can go into women's bathroom," and he replied "if I knew that I could long ago shower with the girls during gym, then I would have identified as a woman a lot sooner." Thank you for letting me know that you are actually a sexual predator, and that you would do anything to find a legal loophole in order to sexually assault women 
Kohl 2.1

in the bathroom. That didn't tell me anything about trans-people, but it told me a lot about you.

Jana: $\quad$ So again, my presence with you in the office means that I am a sexual object for you. This reminds me of something I had read "in the Bible, to know a woman is to have sex with her. You acquire carnal knowledge. FEMINISTS ARE BEGINNING TO UNDERSTAND THAT TO KNOW HAS MEANT TO FUCK." 2 There is a very strong connection with what we are talking about: knowing the other's body is actually sleeping with them. There is no boundary between the different forms of knowledge, and invading her own physical space.

\section{SPEAKING AS RESISTING}

Jana: $\quad$ On the other hand, while men openly speak about their sexual lives, women don't. I am not generalizing; I am talking about women in Beirut, middle to high income, educated, Hamra, bourgeois, lefties... Talking about sexuality is not "normal" in the sense that we don't talk about our own sexual experience. It is as if it's not needed amongst women. We are conditioned to find no reason to talk about sexuality.

Khali: Is there a pressure on you on how one should be? Does this bashing happen amongst women or do they feel that is has to be brought up in a conversation?

L.: $\quad$ It is best to avoid that. I have been socialized as a woman. You don't want to talk about how many sexual exploits you've had or would do, you will eventually, but it depends on how much you trust.

Jana: $\quad$ Exactly, most of the time, it's between two women. It wouldn't easily be in a group. It becomes as if you are all sitting naked with one another.

L.: $\quad$ You are right. Because it is not the end goal of that gender group. A man's best chance would be to increase in prestige, to date one woman/women who are near to the ideal of beauty.

Jana: $\quad$ We still don't talk about our sexuality. We talk to male friends about our sexual lives much easier than we talk to our female friends. I don't know what to expect from my female friends, I can't speak to them. I expect so much prejudice, or if she doesn't start the conversation I'd be afraid that she has different opinions.

L.: $\quad$ She probably is afraid of the same thing. Both of you are.

2 MacKinnon, Catharine. 'Feminism, Marxism, Method and the state', Chicago Journals, 1983 
Jana: $\quad$ Exactly, this is where amongst ourselves, we are regenerating the same dynamics of hegemony.

L.: $\quad$ We are imposing it on one another. This reminds me of Foucault's Discipline and Punishment. It really applies. You become your own oppressor and other people's oppressor.

Jana: $\quad$ For me, this is very oppressive because it eliminates a whole form of enjoyment that I have with other women and that I can't share. I can't share this with my mother, with women in my family, etc. That is one sort of violence against me as a woman and it totally deforms the kind of relationship I have with women in my life generally.

Khalil: $\quad$ You can only share it if it was socially approved. In a normative relationship of marriage, it does happen.

L.: $\quad$ The subtext would be: you feel more comfortable talking about this to men. You know that men won't be penalized, but when you talk about it to a woman, if she accepts your behavior, that is going to say something about her in the eyes of other people: "You are her mother and you accept that she says and does something like that." Now she is in that position because she accepted you, so you have also othered your mother, or any woman, because let us not forget that they are also under scrutiny.

\section{LANGUAGE}

Jana: $\quad$ Curse words, the use of body parts to humiliate the other, but also the use of sex as an action of dominion and violence. So telling a man "I want to fuck your sister," how is that bad? When it comes from a man, it is an act of violence towards the women in one's family.

Khali: It is an act of war, when you use the expression of "al Fat'h-al Ghazw,"3 which is compared to sleeping with a virgin. It is about control and accessing a space which is supposed to be pristine and well-protected.

L.: $\quad$ It is not only an act of violence but it is also based on the concept of ownership. "I will fuck your mother," which is supposed to mean that even if she was an older member, she still needs to consult you. It is about dominion too

\footnotetext{
3 الفتح-الغزو: terms used to indicate occupation, having "opening" as a direct translation
} 
Kohl 2.1

Jana: $\quad$ We can compare it to a herd: "I will now take your herd. It belonged to you, from now on, it will belong to me."

Serena: $\quad$ Taking one's agency away.

L.: $\quad$ But also throughout history, what colonizers would do: acquiring the first night's right.

Jana: It is interesting to see how this is replicated unto our discourse about the land, occupation and liberation. "Palestine is the raped land" in Arabic. She is a woman, always, and the liberator is the man. And also why is sex an act of violence as a social act, other than the dominion paradigm?

Khalil: With the mentality of conquest, when will one be able to sleep with the women? It is only after all the defenses are destroyed that one can access, use, and enjoy the games of war. I think the term started being used when so much destruction had taken place, so that the sacred space can be accessed.

L.: $\quad$ And they are "penetrated," "invaded," and this is practically supposed to make one defend their "mother-land."

Jana: $\quad$ But talking about "sex as oppression and subjugation," why is kneeling to the ground something "negative?"

L.: $\quad$ A form of subjugation? From a simple aspect, spatially, it means "who is on top?"

Jana: $\quad$ And it could be one way of explaining that men don't accept not to be on top. So why does physical subjugation, when related to the bodies' spatial position, mean dominion?

Khalil: Habit. From a martial arts perspective, if I am fighting, the one in control is on top.

Jana: $\quad$ So it is control and the fact that we perceive sexual act as power-related.

\section{PORN}

Jana: In which sense can porn and sex work function as an act of liberation for women, or not?

L.: $\quad$ I think when they are no longer sanctioned and condemned by men.

Jana: Which means that till now, they have never been liberating? 
L.: $\quad$ In that sense, no. In terms of smaller scale acts of agency, maybe, it would have to be. But we know that the highest demand for sex workers come from cis-gender men. These are also men who think of sex work as a degrading occupation. But at the same time, they are part of the demand. Nobody actually questions men's entitlement to both the creation of "this" when it suits its agenda, and condemning it when it doesn't.

Jana: $\quad$ Do you think it could be an act of liberation for the sex workers and porn actors themselves, Serena?

Serena: $\quad$ It has to do with how much agency they have in it, and choice

L.: $\quad$ And even if they have high levels of agency, it could be their decision to do this. But then again, everybody forgets for a moment, everybody seems to forget that women are blamed, judged, and held responsible for things. So it can be liberating in small scale instances in the choice we have to use our bodies the way we want, maybe to get money, and everybody needs to respect that, but the problem is nobody does. Nobody respects that.

Jana: I also think that the arguments used are hypocritical: it is either through representing her as a victim of the society, financial situation, etc., or treating her like a monster because she "loves" her job. I agree with you, until this job is treated the same way l'm being treated for selling my ideas, only then can this be fully liberating. And the women are much more powerful whenever it is legalized.

L.: $\quad$ The problem is that for the system, whenever something becomes legal, it becomes visible.

Khalil: $\quad$ And how do you control things? You keep people vulnerable, and you use it. We are all vulnerable in different situations, but we are not as vulnerable as those who are perceived as illegal and immoral at the same time. That control is needed, the one that makes them lose their vulnerability, that who makes them visible, able to mobilize, to ask for their rights...

L.: $\quad$ Because it gives them a platform where this can actually become a conversation; it is given a space to become a conversation. All disenfranchised groups know what it is to have an oppressor, but that doesn't stop them from oppressing one another. And it is also interesting to see how some disenfranchised and marginalized groups deserve more attention than other disenfranchised and marginalized groups. You always have to give play to more powerful groups to assert their place within a society.

Jana: $\quad$ And we get to discover how much hierarchies there are, even within the marginalized communities themselves. 